Corrigendum

\title{
Corrigendum to "Vegetation development in the Middle Euphrates and Upper Jazirah (Syria/Turkey) during the Bronze Age" [Quaternary Research 74 (2010) 216-226]
}

\author{
Katleen Deckers ${ }^{\mathrm{a}, *}$, Hugues Pessin ${ }^{\mathrm{b}}$ \\ a University of Tübingen, Zentrum für Naturwissenschaftliche Archäologie, Rümelinstr. 23, 72070 Tübingen, Germany \\ b University of Sheffield, Department of Archaeology, Northgate House, West St., Sheffield S1 4ET, UK
}

The charcoals from two Tell Leilan samples mentioned as dating to the Late Bronze Age (1400-1200 BC) in Deckers and Pessin (2010) can no longer be assigned to this period. Recently, two radiocarbon dates were obtained from charcoal fragments in response to querries regarding the two samples. The context of concern was a (burial?) pit that contained Late Bronze Age (Middle Assyrian) sherds.

Two short-lived samples were submitted to the Kiel laboratories, a twig of Populus/Salix from sample L06-44V13, 6.1 that was labeled KIA43102, and a twig of Vitis from sample L06-44V13, lot 16, N 6 that was labeled KIA43103. They provided AMS radiocarbon dates of, respectively, $3790 \pm 27$ ${ }^{14} \mathrm{C}$ yr BP (2296-2138 BC) and $3772 \pm 34{ }^{14} \mathrm{C}$ yr BP (2294-2126 BC or 2090-2044 BC) (calibrated using CALIB rev. 5.01). Even if - as was indicated by the excavators - later Middle Assyrian pottery was possibly included in these pit contexts, the charcoals as a whole can no longer be assigned to this period. Therefore, the results for Leilan regarding the Late Bronze Age (1400-1200 BC) in Deckers and Pessin (2010) should be dismissed. Overall, however, this does not greatly impact the general conclusion because, at the outset, not much weight was placed on these results; only these scant two samples were investigated from Tell Leilan in the alleged period. In contrast, many more samples were successfully collected and considered from most of the other sites and periods.

DOI of original article: 10.1016/j.yqres.2010.07.007.

* Corresponding author.

E-mail address: katleen.deckers@uni-tuebingen.de (K. Deckers). 